\title{
O COMPLIANCE NA EFETIVAÇÃO DOS DIREITOS FUNDAMENTAIS DA MULHER NO ÂMBITO EMPRESARIAL
}

\author{
COMPLIANCE IN THE EFFECTIVENESS OF WOMEN'S FUNDAMENTAL \\ RIGHTS IN BUSINESS
}

SANDRA REGINA MARTINI ${ }^{1}$

CLAYTON REIS ${ }^{2}$

BEATHRYS RICCI EMERICH ${ }^{3}$

\section{RESUMO}

O projeto intitulado, "O compliance na efetivação dos direitos fundamentais da mulher no âmbito empresarial" trata da discussão sobre os direitos da mulher nas empresas. É uma questão nova e representa um novo paradigma, os direitos da mulher no âmbito empresarial tornam-se o centro das atenções como elemento definidor não só de uma nova era da sociedade, mas também de uma revisão antropológica da relação homem-trabalho-mulher. O presente estudo objetiva investigar como o compliance pode contribuir para a efetivação dos direitos e garantias fundamentais no ambiente empresarial em âmbito geral. Dentre os objetivos específicos, a pesquisa visa compreender aplicabilidade do compliance nas organizações, em caráter preventivo, diante dos desafios no ambiente de trabalho; identificar a promoção da responsabilidade empresarial sobre os direitos da mulher no trabalho através do compliance e pesquisar as possibilidades de apoio e respeito à dignidade da mulher no ambiente empresarial. $\mathrm{O}$ estudo bem sendo realizado mediante a abordagem qualitativa que se caracteriza pela pesquisa primária documental, com o intuito de ampliar os conhecimentos, fundamentando-se no estudo de referenciais teóricos, tendo empregado onde as contradições se transcendem dando origem a novas contradições que requerem soluções. No ponto de vista dos objetivos metodológicos deste estudo, o tipo de pesquisa que é extrapolatória com vista a proporcionar maior familiaridade com um problema em razão de escolhermos para procedimentos técnicos de investigação o levantamento bibliográfico, elaborada a partir de consultas acerca do entendimento de constitucionalistas e juristas e empreendedores sobre a aplicabilidade do compliance na efetivação dos direitos fundamentais da mulher no âmbito empresarial, bem como utilização de artigos acadêmicos em sítios da internet apropriados. Assim, a metodologia a ser adotada será a dedutiva, isto é, análises de doutrinas, artigos e legislações.

\footnotetext{
${ }^{1}$ Possui graduação em Ciências Sociais pela Universidade do Vale do Rio dos Sinos (1983), mestrado em Educação pela Pontifícia Universidade Católica do Rio Grande do Sul (1997), doutorado em Evoluzione dei Sistemi Giuridici e Nuovi Diritti pela Università Degli Studi di Lecce (2001), Pós-doutorado em Direito (Roma Tre, 2006) e Pós-doutorado em Políticas Públicas (Universidade de Salerno, 2010). Foi Professora titular da Universidade do Vale do Rio dos Sinos, da Scuola Dottorale Internazionale Tullio Ascarelli e professora visitante da Universita Degli Studi Di Salerno

${ }^{2}$ Doutor em Direito pela Universidade Federal do Paraná (1999). Mestre em Direito pela Universidade Federal do Paraná (1996). Bacharel em Direito pela Faculdade de Direito de Curitiba (1970). Magistrado em Segundo Grau, aposentado, do TJPR. Professor na Escola da Magistratura do Paraná e pertence ao Corpo Docente Permanente do Programa de Mestrado em Direito Empresarial e Cidadania do UNICURITIBA. Realizou estágio Pós-doutoral na Faculdade de Direito da Universidade de Lisboa-Portugal (2013).

${ }^{3}$ Graduada em Direito pela Pontifícia Universidade Católica do Paraná (2017). Pós-graduada em Direito Aplicado pela Escola da Magistratura do Paraná (2018). Atualmente é advogada e mestranda em Direito Empresarial e Cidadania pelo Centro Universitário Curitiba (Unicuritiba).
} 
Além disso, será empregado o método indutivo devido com a análise de jurisprudências acerca do tema até o presente momento. $\mathrm{O}$ estudo de tal temática, tão vasta e complexa representa um desafio, como demonstram as diversas investigações multidisciplinares das áreas, que, sob diferentes enfoques e perspectivas, vêm continuamente tentando avançar a compreensão teórica do assunto. $\mathrm{O}$ estudo deste fenômeno e sua aplicabilidade na esfera juslaboral exigem prévia contextualização do instituto e sua evolução no tempo como condição para entender seus fundamentos, sua função teleológica, e, por fim, a verificação da sua efetividade sob o viés da proteção dos direitos fundamentais da mulher quando empoderamento das mulheres e promoção da equidade de gênero em todas as atividades sociais e da economia, como também da prevenção de eventuais prejuízos, ou ainda da benesse de alguma legislação vigente através das técnicas de consultorias/planejamento. O estudo em questão pretende contribuir para o entendimento dos avanços conquistados no âmbito de políticas públicas no Brasil, no que diz respeito às questões de gênero.

Palavras-chave: compliance; direitos da mulher; direitos fundamentais.

\begin{abstract}
:
The assignment entitled "The Compliance in the accomplishment of woman's fundamental rights in business environment" deals with the discussion on women's rights in companies. It is a new issue and represents a new paradigm. The rights of women in business sphere become the center of attention as a defining element not only of a new era in society but also of an anthropological review of the man-woman work relationship. This study aims to investigate how compliance can contribute to the accomplishment of women's fundamental rights and guarantees in general business environment. Among the specific objectives, the research aims to understand the applicability of compliance in companies, as a preventive purpose in the light of the challenges in work environment, identify the promotion of corporate responsibility for women's rights at work through compliance, and examine the possibilities of support and respect for the dignity of women in business environment. The study has been carried out through the qualitative approach that is characterized by primary documentary research with a view to expand knowledge, based on the study of theoretical references. These references will be used where the contradictions transcend and lead to new contradictions that require solutions. Seeing through the methodological point of view, this is an exploratory research that aims to increase familiarity with a new problem. For this reason, we chose revision of the literature as technical investigation procedure. This bibliographical survey will be elaborated from consultations about the understanding of constitutionalists, jurists and entrepreneurs on the applicability of compliance in the accomplishment of women's fundamental rights in business environment. The bibliographical survey will also use academic articles on appropriate websites. Thus, the methodology used in this study is deductive, the analysis of legal doctrines, articles, and legislation. However, this study also uses the inductive method that involves an analysis of jurisprudence on the subject up to the present. The study of such a broad and complex topic represents a challenge, as demonstrated by diverse multidisciplinary investigations of the areas, which, under different approaches and perspectives, have been continuously trying to advance the theoretical understanding of the institution. The study of this phenomenon and its applicability in the labor law require prior contextualization of the topic and its evolution over time as a condition to understand its fundamentals and its teleological function, and, finally, to verify its effectiveness on the protection of women fundamental rights, within the sphere of women's empowerment and promotion of gender equality in all social and economic activities, and the prevention of possible losses, as well the benefits of current legislation through consultancy-planning techniques. This study intends to contribute to the understanding of the advances achieved at the level of public policies in Brazil concerning gender issues.
\end{abstract}

Keywords: compliance; women's rights; fundamental rights.

\title{
1 INTRODUÇÃO
}

O presente trabalho tem o objetivo de abordar em que circunstâncias a atividade empresarial encontra sua liberdade de ação protegida pela Constituição. A cada ano, as questões 
do empoderamento feminino e de como as mulheres vem, cada vez mais, ocupando espaço, na sociedade e nas empresas.

Nesse cenário, a partir do século XIX, as mulheres passaram a se incorporar no mercado de trabalho. Com a revolução industrial a mão-de-obra feminina passou a ser muito importante dentro das fábricas para operar as máquinas. Assim, essa pesquisa visa mostrar que com o passar dos anos as mulheres estão se inserindo de forma significativa no mercado de trabalho.

As razões que tornam importante a realização da pesquisa proposta é compreender como os direitos da mulher no âmbito empresarial tornam-se o centro das atenções como elemento definidor não só de uma nova era da sociedade, mas também de uma revisão antropológica da relação homem-trabalho-mulher.

Assim, o objetivo geral a ser estudado nessa pesquisa, pretende investigar como o "compliance" pode contribuir para a efetivação dos direitos e garantias fundamentais no ambiente de trabalho em âmbito geral e, também, empresarial.

Assim, na primeira parte deste artigo, será necessário compreender a história e evolução da mulher no mercado de trabalho, bem como sua posição e proteção no âmbito empresarial. Em seguida, a pesquisa abordará a igualdade entre os homens e mulheres no mercado de trabalho e quais as regulamentações e políticas públicas que vem sendo adotadas para mudar o cotidiano da mulher.

Por fim, o trabalho tratará do "compliance" como aliado da mulher na atuação profissional e qual sua importância para o empoderamento feminino no âmbito empresarial. Com isso, este trabalho tem como problema de pesquisa identificar "qual a contribuição do “compliance" para a efetivação dos direitos fundamentais da mulher no âmbito empresarial? ”.

Feitas essas ponderações introdutórias, pode-se constatar a complexidade e a relevância da questão objetivada neste trabalho, pelo qual não tem o desígnio de esgotar o assunto, mas apenas, de trazer alguns apontamentos iniciais e importantes acerca do "compliance" e dos direitos fundamentais da mulher no âmbito empresarial.

\section{HISTÓRIA E EVOLUÇÃO DA MULHER NO MERCADO DE TRABALHO}

A ideia de Compliance no Brasil é recente e pode ser observada sutilmente a partir da Constituição da República Federativa do Brasil de 1988, assim como seus posteriores pactos internacionais nos quais o Brasil faz parte. 
Desde o século XVII, quando o movimento feminista passou a adquirir características de ação política, as mulheres vêm tentando realmente colocar em prática essa lei. Desde então, pesquisas recentes comprovam que o número de mulheres em postos diretivos vem crescendo exponencialmente nas empresas. Curiosamente, essa ascensão se dá em vários países, de maneira semelhante ${ }^{4}$.

De acordo com Pinto Martins ${ }^{5}$, desde a consolidação do sistema capitalista, no séc. XIX, inúmeras mudanças ocorreram na produção e na organização do trabalho feminino. A revolução industrial acarretou a transferência de boa parte da mão de obra feminina para dentro das fábricas. Além disso, as mulheres sujeitavam-se a jornadas de trabalho excessivas, salários baixos, trabalhando muitas vezes em condições prejudiciais à saúde, tudo para poderem se manter no emprego.

Segundo Mello $^{6}$ (2016) na Idade Média, as mulheres já puderam provar suas habilidades, e um exemplo disto foi Joana D'arc, uma camponesa francesa que comandou parte do exército francês na Guerra dos Cem anos (1337-1453) e se tornou santa e mártir da França.

Porém, somente a partir do séc. XIX, a educação de meninos e meninas passa a ser intensificada. Assim, deste período em diante, a mulher passa a ser vista sob novos aspectos. Seu perfil muda à torna um ser em construção, na busca de realização e desenvolvimento de suas potencialidades ${ }^{7}$.

A introdução da mulher no mercado de trabalho se deu com a I e II Guerra Mundial, quando os homens iam para as batalhas e as mulheres passavam a assumir os negócios da família e a posição dos homens no mercado de trabalho ${ }^{8}$.

Da mesma maneira defende Murardo": "Uma verdadeira revolução, as mulheres invadem o mundo de trabalho masculino, e, tecnicamente, acabam com a separação entre o mundo privado e o público". A inserção das mulheres no mercado de trabalho, é considerado fator de grande estima para a liberdade e a autonomia, somando-se ainda, as atividades cotidianas do lar.

Ainda, segundo Ramos, as mulheres dirigiram-se para os campos de batalha para trabalhar como enfermeiras, cozinheiras, motoristas de ambulâncias e etc.. Assim, as guerras

\footnotetext{
4 PROBST, Elisiana Renata. A Evolução da Mulher no Mercado de Trabalho. Disponível em: https://www.rhportal.com.br/artigos-rh/a-evoluo-da-mulher-no-mercado-de-trabalho/. Acesso em: 18 jan. 2020.

${ }_{5}^{5}$ MARTINS, Sérgio Pinto. Direito do Trabalho, 24 ed. São Paulo, Atlas, 2008, p. 477.

${ }^{6}$ MELLO, A. C. R. C. D. As mulheres na Guerra. Revista Pré UNIVESP, n. 61, dez. 2016.

${ }^{7}$ LESKINEN, M.: Educación una clave hacia la igualdad, Revista Observatório Social, n. 5, 2004.

${ }^{8}$ Ibidem.

${ }^{9}$ MURARDO, R. M.: La mujer en el tercer milenio: una historia de la mujer a traves de lo tiempo y perspectiva para el futuro, Rio de Janeiro, ed. Rosa de los Tiempos, 1992, p. 1.
} 
deram oportunidades as mulheres, pois em vários países, elas puderam se consolidar como profissionais e adquirir independência financeira ${ }^{10}$.

\title{
2.1. A POSIÇÃO DA MULHER NO MERCADO DE TRABALHO
}

Movidas pelo anseio de contribuir para a manutenção da família, ou mesmo pelo almejo de obter sucesso profissional, as mulheres estão cada vez mais presentes no mercado de trabalho.

Pesquisas recentes comprovam como a participação da mulher no mercado de trabalho vem aumentando, bem como sua responsabilidade de ajudar no sustento da família e também o seu destaque profissional em vários setores ${ }^{11}$.

Segundo pesquisas realizadas pelo Ministério do Trabalho ${ }^{12}$ :

\begin{abstract}
"A participação das mulheres no mercado formal de trabalho passou de 40,85\% em 2007 para 44\% em 2016, segundo os dados mais recentes da Relação Anual de Informações Sociais (Rais), do Ministério do Trabalho. No mesmo período, as trabalhadoras reduziram de $17 \%$ para $15 \%$ a diferença salarial em relação aos homens.

Dos 46,1 milhões de empregos formais registrados na Rais em 2016, os homens somavam 25,8 milhões de vínculos empregatícios (56\% do estoque de empregos no ano), e as mulheres, 20,3 milhões (44\%). Dez anos antes, em 2007, os homens respondiam por $59,15 \%$, e as mulheres, por 40,85\% dos 37,6 milhões de postos de trabalho. [...]"
\end{abstract}

Para o ministro do Trabalho, Helton Yomura, os dados mostram uma tendência na redução das desigualdades no mercado de trabalho: "Apesar de ainda existir diferença na participação e na remuneração entre homens e mulheres, as mulheres vêm conquistando um espaço cada vez maior na economia formal do país".

Segundo, ainda, o Sistema Estadual de Análise de Dados (SEADE) ${ }^{13}$, vem ocorrendo um crescimento constante no mercado de trabalho feminino em todas as faixas etárias. Ademais, a Fundação Seade mostra que, em meados de 1994, 35\% das mulheres contavam com o ensino médio completo. Ao final da década de 90 , esse número aumentou para $43 \%$.

${ }^{10}$ RAMOS, G. S. Leitura feminista da história do Brasil. Rev. Estudos Feministas, v.21, n.3, Florianópolis, 2013.

${ }^{11}$ ZILLI, S. M.: Mujer, discriminación y derecho del trabajo, Rev. Observatório Social, n.5, 2004

${ }^{12}$ BRASIL. Ministério da Economia. Em dez anos, cai diferença entre homens e mulheres no mercado de trabalho. Disponível em: http://trabalho.gov.br/noticias/5497-em-dez-anos-cai-diferenca-entre-homens-emulheres-no-mercado-de-trabalho-2. Acesso em: 19 jan. 2020.

13 Fundação Sistema Estadual De Análise De Dados - SEADE. Disponível em: https://www.seade.gov.br/produtos/mulher-trabalho/. Acesso em: 19 jan. 2020. 
Ainda, para o Ministério da Mulher, da Família e dos Direitos Humanos:

\begin{abstract}
"A divisão sexual do trabalho é a divisão de atribuições, tarefas e lugares sociais para mulheres e homens, decorrentes das relações sociais de sexo. Essa forma é historicamente adaptada a cada sociedade e tem por característica a destinação prioritária dos homens a atividades produtivas (ocupações de forte valor social agregado, como comércio, indústria, empreendimentos, e na política) e a mulheres à esfera reprodutiva (atividades relacionadas a cuidados e afazeres domésticos). Essa divisão repercute fortemente nos cargos e funções ocupados pelas mulheres e em seus rendimentos, já que são destinadas às mulheres principalmente tarefas e ocupações que remetem a cuidado e serviços que são menos valorizados socialmente. ${ }^{14}$ ”
\end{abstract}

Nesse sentido, importante refletirmos sobre como a divisão sexual do trabalho tece a divisão social do trabalho, de modo que homens e mulheres participam de modo desigual da produção e da reprodução na sociedade.

Para Martins ${ }^{15}$, a divisão sexual do trabalho não seria apenas um status de subordinação feminina em relação aos homens nas relações de trabalho, mas sim a de reprodução de padrões que promovem a inferioridade em relação aos homens dentro das mais diversas dimensões que caracterizam a desigualdade de gênero.

\title{
2.2 PROTEÇÃO À MULHER TRABALHADORA
}

A Central Única dos trabalhadores (CUT) criou uma Secretaria Nacional Sobre A Mulher Trabalhadora, a qual compete elaborar, coordenar e desenvolver políticas para promoção de mulheres trabalhadoras na perspectiva das relações sociais de gênero, raça e classe, subsidiando as instâncias horizontais e verticais e as entidades filiadas nos seus respectivos âmbitos.

Bezerra Lima ${ }^{16}$ defende que:

\begin{abstract}
"Nossas estratégias para superar a discriminação e a exclusão social passam por identificar temas importantes e prioritários que contribuam para a igualdade de oportunidades no mundo do trabalho e sindical. As demandas de trabalhadoras e trabalhadores são diferenciadas dada a divisão sexual do trabalho e as relações de
\end{abstract}

\footnotetext{
${ }^{14}$ BRASIL. Ministério da Mulher, da Família e dos Direitos Humanos. O que é Divisão Sexual do Trabalho e como ela incide nas relações de trabalho? Disponível em: https://www.mdh.gov.br/navegue-portemas/politicas-para-mulheres/arquivo/arquivos-diversos/acesso-a-informacao/perguntas-frequentes/perguntasfrequentes-sae/o-que-e-divisao-sexual-do-trabalho-e-como-ela-incide-nas-relacoes-de-trabalho. Acesso em: 19 jan. 2020.

${ }^{15}$ MARTINS, Clitia H. B.; BANDEIRA, Marilene D.; CAPUTO, Paula M.. Condição de vida das mulheres e desigualdades de gênero no Rio Grande do Sul. In: MARTINS, Clitia H. B. (Coord.). Estudos das condições das mulheres e das desigualdades de gênero existentes no Estado do Rio Grande do Sul - Porto Alegre: FEE, 2013, p. 108.

${ }^{16}$ BEZERRA LIMA, M. E.: Organización de las mujeres en la CUT, Revista Observatório Social, n. 5, 2004.
} 
poder. Por isso é fundamental considerar a situação concreta das mulheres para a formulação do conjunto das políticas e da intervenção sindical".

E, conforme afirma Delgado ${ }^{17}$, o princípio da proteção do trabalhador, por sua vez, está intimamente ligado com o princípio da dignidade da pessoa humana, "princípio maior do Direito Constitucional contemporâneo, espraiando-se, com grande intensidade, no que tange à valorização do trabalho".

\section{3 (DES)IGUALDADE ENTRE HOMENS E MULHERES NO MERCADO DE TRABALHO}

Segundo Hirata \& Kergoat, uma análise em termos de divisão sexual do trabalho deve levar em conta dois princípios organizadores: (a) um princípio de separação, de distinção entre o masculino e o feminino (diferenciando trabalhos de homens e trabalhos de mulheres); e, (b) um princípio de hierarquização entre essas categorias, de tal forma que "um trabalho de homem vale mais que um trabalho de mulher" ${ }^{\prime 18}$.

Na visão de $\operatorname{Santos}^{19}$, do ponto de vista social, o conceito de gênero ainda é novo, desenvolvido a partir do movimento feminista, enquanto que as relações de gênero possuem raízes mais anteriores ao movimento feminista.

De acordo com Bruschini em o "Tesauro para estudos de gênero", o conceito de gênero é exposto como sendo:

\footnotetext{
"Princípio que transforma as diferenças biológicas entre os sexos em desigualdades sociais, estruturando a sociedade sobre a assimetria das relações entre homens e mulheres. Usar "gênero" para todas as referências de ordem social ou cultural, e "sexo" para aquelas de ordem biológica. "20
}

\footnotetext{
${ }^{17}$ DELGADO, Maurício G.; DELGADO, Gabriela N. O princípio da dignidade da pessoa humana e o Direito do Trabalho. In: Diálogos entre o Direito Trabalho e o Direito Constitucional: estudos em homenagem a Rosa Maria Weber. SARLET, Ingo Wolfgang; MELO FILHO, Luiz Philippe Vieira de; FRAZÃO, Ana de Oliveira (Coords.). São Paulo: Saraiva, 2014, p. 208.

${ }^{18}$ HIRATA, H. \& KERGOAT, D. Divisão sexual do trabalho profissional e doméstico: Brasil, França, Japão. In: COSTA, A., SORJ, B., BRUSCHINI, C., HIRATA, H. (Org.). Mercado de trabalho e gênero: comparações internacionais. Rio de Janeiro: Editora FGV, 2008, p. 266.

${ }^{19}$ SANTOS, Juliana A. dos. Desigualdade social e o conceito de gênero. Virtú (UFJF), v. 1, p. 1/3, 2006.

Disponível em: http://www.ufjf.br/virtu/files/2010/05/artigo-3a7.pdf. Acesso em: 18 jan. 2020.

${ }^{20}$ BRUSCHINI, Cristina; ARDAILLON, Danielle. Tesauro para estudos de gênero e sobre mulheres. São Paulo: Fundação Carlos Chagas, 1998.
} 
Dessa forma, parafraseando $\operatorname{Sen}^{21}$ na obra "desigualdade reexaminada": "a ética da igualdade tem de levar em conta adequadamente nossas diversidades generalizadas, que afetam as relações entre os diferentes espaços". Assim, devido à diversidade humana, a pluralidade das variáveis de foco (focais) pode fazer uma grande diferença.

\subsection{POLÍTICAS PÚBLICAS PARA MUDAR O COTIDIANO DA MULHER}

No Brasil, as transformações domésticas e internacionais são propulsoras de avanços significativos em diversas áreas, dentre elas o combate à violência e o empoderamento econômico das mulheres.

Nas palavras da Ministra Nilcéia Freire ${ }^{22}$ : “as mulheres têm pouca presença nas posições mais altas e estão excessivamente presentes nos cargos não-especializados, estamos sub-representadas nos cargos bem pagos e excessivamente presentes nos mal pagos".

Segundo Pereira ${ }^{23}$, os homens e mulheres buscam se organizar politicamente, com a finalidade de atingirem seus objetivos comuns e, assim, se distanciarem do caos que poderia ocorrer se cada um enfrentasse na defesa de seus interesses e objetivos particulares. $\mathrm{Na}$ configuração recente de política pública, existe uma conotação de política pública, a qual Pereira defende, ainda, como sendo uma: “[...] ação pública, na qual, além do Estado, a sociedade se faz presente, ganhando representatividade, poder de decisão e condições de exercer o controle sobre a sua própria reprodução e sobre os atos e decisões do governo."

O Brasil iniciou o reconhecimento do sufrágio feminino muito tardiamente. O marco inicial das discussões parlamentares acerca do tema se deu em meados de 1824. Neste Constituição não havia nenhum impedimento contra o exercício dos direitos políticos das mulheres, porém também não havia nada explícito sobre esse exercício. Com efeito, apenas durante o Governo Provisório de Getúlio Vargas, com a aprovação do Decreto n. 21.076, que as mulheres obtiverem o direito de votar. Nas palavras de Bezerril:

“O decreto garantia cidadania políticas às mulheres e uma ampliação significativa no
número de votantes no país. As mulheres, que desde o início do século passado haviam
sido tocadas pelo 'afã da campanha abolicionista', despertaram de sua antiga condição
de intolerância e passividade, ampliando o horizonte do espaço doméstico e familiar,
lançaram-se às novas lutas e conquistas, reivindicando maior acesso à instrução e ao

\footnotetext{
${ }^{21}$ SEN, Amartya. Desigualdade reexaminada. Rio de Janeiro: Editora Record, 2001.

${ }^{22}$ FREIRE, N.: Politicas Publicas hacia cambiar el cotidiano de la mujer. Revista Observatório Social, n. 5, 2004.

${ }^{23}$ PEREIRA, P. A. P. Discussões conceituais sobre política social como política pública e direito de cidadania. In: BOSChetTI, I.; BeHRING, E. R.; SANTOS, S. M. M.; MIOTO, R. C. T. (orgs.). Política Social no Capitalismo: tendências contemporâneas. São Paulo: Cortez, 2008, p. 94.
} 
conhecimento, um lugar no mercado de trabalho e o direito de participar diretamente da soberania nacional. " 24

A Organização Internacional do Trabalho (OIT), comprometida a eliminar a discriminação e a promover a igualdade no mundo do trabalho, promove a implementação de padrões de trabalho relacionados à igualdade de gênero. Além disso, fornece conselho técnico para os governantes, de modo a dar mais segurança aos sistemas estatísticos nacionais. Para que, assim, computem o trabalho que as mulheres fazem e que as reformas às leis trabalhistas e aos sistemas de relações industriais não ampliem as desigualdades de gênero ${ }^{25}$.

Hierarquicamente, a divisão sexual do trabalho interfere diretamente nas possibilidades de participação política das mulheres. Isto porque corresponde à alocação desigual de recursos fundamentais para essa participação, principalmente no tocante ao tempo livre e a remuneração. ${ }^{26}$

O artigo $5^{\circ}$, inciso I, da Constituição da República prevê que "homens e mulheres são iguais em direitos e obrigações, nos termos da Constituição. "27 Dessa forma, igualdade de gênero é, portanto, direito fundamental constitucionalmente assegurado.

Com a finalidade de cumprir o que estabelece a Constituição Federal, o Supremo Tribunal Federal decidiu na ADI $1946^{28}$, excluir do teto, o valor dos benefícios do regime geral de previdência social, o salário da licença gestante. Tendo o julgado se fundamentado na seguinte explanação:

\footnotetext{
"se se entender que a Previdência Social, doravante, responderá apenas por $\mathrm{R} \$ 1.200,00$ (hum mil e duzentos reais) por mês, durante a licença da gestante, e que o empregador responderá, sozinho, pelo restante, ficará sobremaneira, facilitada e estimulada a opção deste pelo trabalhador masculino, ao invés da mulher trabalhadora. Estará, então, propiciada a discriminação que a Constituição buscou combater, quando proibiu diferença de salários, de exercício de funções e de critérios de admissão, por motivo de sexo (art. $7^{\circ}$, inc. XXX, da CF/88). Estará, ainda, conclamado o empregador a oferecer à mulher trabalhadora, quaisquer que sejam suas aptidões, salário nunca superior a R\$1.200,00, para não ter de responder pela diferença”"
}

\footnotetext{
${ }^{24}$ BEZERRIL, F. D. F. Entre o privado e o público: espoco para uma história política do direito ao voto feminino. Monografia (Graduação em Ciências Sociais). Universidade Federal de Paraíba, 2008, p. 58.

${ }^{25}$ TOMEI, Manuela. El trabajo de la OIT hacia alcanzar la igualdad de gênero. Revista Observatório Social: São Paulo, n. 5, 2004, p. 51.

${ }^{26}$ BIROLI, Flávia. Gênero e desigualdades. Limites da democracia no Brasil. São Paulo: Boitempo, 2018 , p. 44.

${ }^{27}$ BRASIL. Constituição (1988). Constituição da República Federativa do Brasil. Brasília, DF: Senado Federal: Centro Gráfico, 1988.

28 ADI 1946, Pleno, Rel. Min. Sydney Sanches, julgado em 03/04/2003. p. 130. Disponível em: http://redir.stf.jus.br/paginadorpub/paginador.jsp?docTP=AC\&docID=266805. Acesso em: 14 dez. 2019.
} 
Dessa forma, compreende-se que a política pública se torna cada vez mais necessária na busca pela resolução de conflitos existentes na sociedade, bem como para criar e garantir o acesso de todos aos direitos.

\section{O COMPLIANCE COMO ALIADO DA MULHER NA ATUAÇÃO PROFISSIONAL}

\subsection{DEFINIÇÃO DO TERMO COMPLIANCE}

Para Hilst ${ }^{29}$, Compliance, além de simples observância da lei e marcos regulatórios, tem por objetivo esclarecer uma cultura na empresa com a finalidade de mitigar o risco atrelado à reputação e o risco legal. Sendo assim, os funcionários do setor de compliance têm a função de assegurar que a empresa esteja cumprindo as regras aplicáveis a cada negócio, de maneira que cada empresa possui uma forma adequada de Programa de Compliance.

Segundo definição dada pelo Doutor em Direito Mateus Bertoncini ${ }^{30}$, o termo Compliance:

“[...] refere-se à postura consentânea à determinada regra, o que traduz uma acepção ampla em termos de cumprimento e observância normativa. Na esfera empresarial, o compliance pode se manifestar de diversas formas. Uma delas, relativamente usual, consiste em explicitar em instrumentos, tais como códigos, diretrizes, regulamentos, cartilhas, etc., toda sorte de comandos e instruções, cujo fator conformidade/observância é seu núcleo. A inteligência do compliance é de teor preventivo e tem por objetivo evitar a ocorrência de infrações ao conteúdo que alerta.

O Guia Programas de Compliance do Conselho Administrativo de Defesa Econômica - $\mathrm{CADE}^{31}$ explicita algumas características comuns dos programas de Compliance, que podem ser implementadas de diversas maneiras, tais como:

a. Comprometimento com a Empresa: Envolvimento da alta direção, Recursos Adequados, Autonomia e Independência;

b. Análise de Riscos;

\footnotetext{
${ }^{29}$ HILST, Pedro E. de Lima. Anticorrupção e compliance. Monografia (Bacharelado em Direito) - UFPR, 2013, $110 \mathrm{p}$.

${ }^{30}$ BERTONCINI, Mateus; ARAUJO, A. B. C. . Compliance concorrencial: o controle e o combate às práticas ilícitas do mercado econômico. PERCURSO (CURITIBA), v. 1, p. 306-325, 2018, p. 310.

${ }^{31}$ CONSELHO ADMINSTRATIVO DE DESEFA ECONÔMICA - CADE. Guia de programas de compliance, versão preliminar. Orientações Sobre Estruturação e Benefícios da Adoção dos Programas de Compliance Concorrencial. Disponível em: http://www.cade.gov.br/noticias/cade-apresenta-proposta-de-guia-sobreprogramas-de-compliance-concorrencial/guia-compliance-versao-preliminar.pdf. Acesso: 02 jan. 2020, p. 18-22.
} 
c. Mitigação de Risco: Treinamento e Comunicação Interna, Monitoramento do Programa, Documentação, Punições Internas;

d. Revisão do Programa.

O termo Compliance é originário do verbo em inglês to comply que significa agir de acordo com uma regra. ${ }^{32}$

Consoante $\mathrm{Hsu}^{33}$ (2015, p. 07), no Brasil, o Compliance teve início com a abertura do mercado nacional, em que as empresas brasileiras tiveram que se adequar a padrões internacionais e, desde então, o país passou a fazer parte de diversos dispositivos regulamentares, dentre eles:

- Convenção da Organização para a Cooperação e Desenvolvimento Econômico, ratificada em 2000;

- Convenção Intramericana contra a Corrupção, aprovada no Brasil em 2002;

- Convenção das Nações Unidas contra a Corrupção, aprovada em 2006.

E, internamente, o Brasil criou o antigo COAF - Conselho de Controle de Atividades Financeiras, atual UIF - Unidade de Inteligência Financeira (2019), vinculado ainda ao Ministério da Fazenda.

No âmbito empresarial, a estrutura e um programa de Compliance são determinantes e excepcionais para garantir um ambiente propício nas conquistas das mulheres dentro do ambiente corporativo. O programa tem a missão de adequar as políticas da companhia aos seus princípios e valores, visando sempre combater a discriminação, os abusos e a violência, estimulando, acima de tudo, a igualdade de gênero.

Dessa forma, o Compliance que, no vocabulário corporativo, relaciona-se com os termos conformidade corporativa, abrangendo todos os conjuntos de regras que cada empresa deve observar e cumprir, também inclui assuntos relacionados ao cumprimento de obrigações trabalhistas, ambientais, fiscais, dentre outros.

\subsection{A IMPORTÂNCIA DO COMPLIANCE DE GÊNERO E O EMPODERAMENTO FEMININO NO ÂMBITO EMPRESARIAL}

Primeiramente, é importante definir o que se entende por gênero:

\footnotetext{
${ }^{32}$ HOUAISS, A. (Org.); VILlAR, M. S. (Ed.). Dicionário Houaiss conciso. São Paulo: Moderna, 2011 , p. 85.

${ }^{33}$ HSU, Kerley G. P. Compliance: nova área de atuação para os profissionais do direito. Artigo (Bacharelado em Direito) - UNIT, 2015, p. 07-09.
} 
[...] atributos socialmente construídos, em vez de biologicamente determinados, de mulheres e homens, bem como as relações entre eles em uma determinada sociedade em um momento e local específicos, enquanto o sexo refere-se à diferença biologicamente determinada. As qualidades, identidades e comportamentos esperados de homens e mulheres são determinados através do processo de socialização. ${ }^{34 \text { " }}$ (INTERNATIONAL IDEA et al., 2015, p. 220)

De acordo com o Fórum Econômico Mundial ${ }^{35}$, em 2018 o Brasil caiu cinco posições no ranking de igualdade de gênero, ocupando o $95^{\circ}$ lugar entre os 149 países listados. Dentre as causas que levaram o país a esse lamentável indicador, estão: a participação das mulheres no mercado de trabalho e as oportunidades de renda.

O dia a dia do compliance nas empresas e no cotidiano das mulheres traz reflexos sólidos e eficazes no exercício das atividades profissionais, principalmente por permitir e garantir que elas possam atuar com mais segurança, confiança e igualdade de oportunidades, sem que tenham que renunciar às suas carreiras em virtude das dificuldades e barreiras encontradas em ambientes nocivos e não aderentes à nova realidade e às normas de trato social.

Uma forma de colocar em prática o termo "igualdade de gênero" é preparar a empresa para alinharem-se aos Princípios para o Empoderamento da Mulher ("Women Empowerment Principles - WEP”), definidos pela ONU Mulheres e a Cúpula das Nações Unidas nos termos do Objetivo de Desenvolvimento Sustentável - ODS $5^{36}$.

Nesse sentido, ao assumir gênero como uma categoria de análise, o feminismo contemporâneo se compromete com o objetivo social de se alcançar a igualdade entre gêneros ${ }^{37}$. Por conseguinte, a realização de que a desigualdade não tem relação com a suposta falta de qualificações adequadas das mulheres em assumir determinados cargos, considerados importantes, acarreta em práticas discriminatórias e, consequentemente, em revisões de leis, fazendo com que, assim, tais práticas, sejam repensadas.

\footnotetext{
${ }^{34}$ INTERNATIONAL IDEA; INTER-PARLIAMENTARY UNION; STOCKHOLM UNIVERSITY. Atlas of

Electoral Gender Quotas. International Institute for Democracy and Electoral Assistance,

2013, p. 220. Disponível em: http://www.ipu.org/pdf/publications/atlas-en.pdf. Acesso em: 03 jan. 2020. “[...] socially constructed rather than biologically determined attributes of women and men, as well as the relationships between them in a given society at a specific time and place, while sex refers to the biologically determined difference. The qualities, identities and behaviours expected from men and women are determined through the process of socialization."

35 WORLD ECONOMIC FORUM. The Global Gender Gap Report 2018. Disponível em: http://www3.weforum.org/docs/WEF_GGGR 2018.pdf. Acesso em: 20 jan. 2020.

${ }^{36}$ Organização das Nações Unidas (2017). Glossário de termos do Objetivo de Desenvolvimento Sustentável 5: Alcançar a igualdade de gênero e empoderar todas as mulheres e meninas. Disponível em: https://nacoesunidas.org/wp-content/uploads/2017/06/Glossario-ODS-5.pdf. Acesso em: 20 dez. 2019.

${ }^{37}$ MACDONALD, Fiona. Knocking Down Walls in Political Science. In: Defense of an Expansionist Feminist Agenda. Canadian Political Science Association Conference, 2016. Disponível em: https://cpsaacsp.ca/documents/conference/2016/MacDonald.pdf. Acesso em: 12 dez. 2019.
} 


\section{CONSIDERAÇÕES FINAIS}

Este trabalho teve como objetivo analisar e discutir as diferenças entre mulheres e homens em torno do desenvolvimento social e de gênero, e ponderar como os programas de Compliance contribuem para a diminuição das desigualdades entre ambos, no Brasil.

Apesar do aumento da participação das mulheres no mercado, elas vêm a anos lutando pela igualdade de gêneros no âmbito empresarial, vem ascendendo em profissões e posições genuinamente masculinas e, hoje, conquistou um papel fundamental no crescimento da economia.

Os movimentos das mulheres, ao se organizarem e darem as mãos para lutarem por liberdade, reconhecimento e direito a ter direitos, obtiverem, sem sombra de dúvidas, conquistas e avanços no campo da igualdade de gêneros e a políticas públicas.

Evidentemente que a pesquisa realizada apontou a existência das desigualdades entre gêneros no mercado de trabalho, bem como identificou a luta pelas mulheres na busca pelo seu empoderamento no âmbito empresarial e na sociedade, no âmbito geral.

Todavia, os estudos bibliográficos demonstraram que não restam dúvidas do quão importante é o papel dos Programas de Compliance para o empoderamento feminino, em que medidas e práticas acabam sendo exercidas de modo a racionalizar a desigualdade entre os gêneros tanto dentro como fora do âmbito empresarial. Seguindo essa linha, o compliance é, sem dúvida, um caminho em construção para a prevenção e garantia da melhor a gestão de riscos, agindo com o condão de detectar e interromper condutas irregulares.

Por fim, vale ressaltar que a implementação de programas de Compliance e de políticas públicas que promovam os direitos humanos das mulheres é de responsabilidade tanto do poder público quanto das próprias empresas. Sendo assim, a busca contra tal desigualdade no campo empresarial está intimamente relacionada ao poder público e privado, agindo conjuntamente na busca da dignidade da pessoa humana da mulher. 


\section{REFERÊNCIAS}

ADI 1946, Pleno, Rel. Min. Sydney Sanches, julgado em 03/04/2003. Disponível em: http://redir.stf.jus.br/paginadorpub/paginador.jsp?docTP=AC\&docID=266805. Acesso em: 14 dez. 2019.

BERTONCINI, Mateus; ARAUJO, A. B. C. Compliance concorrencial: o controle e o combate às práticas ilícitas do mercado econômico. PERCURSO (CURITIBA), v. 1, p. 306325, 2018.

BEZERRA LIMA, M. E.: Organización de las mujeres en la CUT, Revista Observatório Social, n. 5, 2004.

BEZERRIL, F. D. F. Entre o privado e o público: espoco para uma história política do direito ao voto feminino. Monografia (Graduação em Ciências Sociais). Universidade Federal de Paraíba, 2008.

BIROLI, Flávia. Gênero e desigualdades. Limites da democracia no Brasil. São Paulo: Boitempo, 2018.

BRASIL. Constituição (1988). Constituição da República Federativa do Brasil. Brasília, DF: Senado Federal: Centro Gráfico, 1988.

BRASIL. Ministério da Economia. Em dez anos, cai diferença entre homens e mulheres no mercado de trabalho. Disponível em: http://trabalho.gov.br/noticias/5497-em-dez-anos-caidiferenca-entre-homens-e-mulheres-no-mercado-de-trabalho-2. Acesso em: 19 jan. 2020.

BRASIL. Ministério da Mulher, da Família e dos Direitos Humanos. O que é Divisão Sexual do Trabalho e como ela incide nas relações de trabalho? Disponível em: https://www.mdh.gov.br/navegue-por-temas/politicas-para-mulheres/arquivo/arquivosdiversos/acesso-a-informacao/perguntas-frequentes/perguntas-frequentes-sae/o-que-e-divisaosexual-do-trabalho-e-como-ela-incide-nas-relacoes-de-trabalho. Acesso em: 19 jan. 2020.

BRUSCHINI, Cristina; ARDAILLON, Danielle. Tesauro para estudos de gênero e sobre mulheres. São Paulo: Fundação Carlos Chagas, 1998.

CONSELHO ADMINSTRATIVO DE DESEFA ECONÔMICA - CADE. Guia de programas de compliance, versão preliminar. Orientações Sobre Estruturação e Benefícios da Adoção dos Programas de Compliance Concorrencial. Disponível em: http://www.cade.gov.br/noticias/cade-apresenta-proposta-de-guia-sobre-programas-decompliance-concorrencial/guia-compliance-versao-preliminar.pdf. Acesso: 02 jan. 2020.

DELGADO, Maurício G.; DELGADO, Gabriela N. O princípio da dignidade da pessoa humana e o Direito do Trabalho. In: Diálogos entre o Direito Trabalho e o Direito Constitucional: estudos em homenagem a Rosa Maria Weber. SARLET, Ingo Wolfgang; MELO FILHO, Luiz Philippe Vieira de; FRAZÃO, Ana de Oliveira (Coords.). São Paulo: Saraiva, 2014.

ELIAS, Fernando Lopes Ferraz. Os mecanismos de indução ao cumprimento do direito internacional à luz da teoria institucionalista das relações internacionais. Revista Jurídica, [S.1.], v. 4, n. 49, p. 116 - 144, nov. 2017. ISSN 2316-753X. Disponível em: 
$<$ http://revista.unicuritiba.edu.br/index.php/RevJur/article/view/2288/1418 >. Acesso em: 25 abr. 2020. doi:http://dx.doi.org/10.21902/revistajur.2316-753X.v4i49.2288.

KNOERR, Fernando Gustavo; MARTINS, José Alberto Monteiro. The contribution of compliance practices to the social role of the company. Revista Jurídica, [S.1.], v. 3, n. 44, p. 1 - 18, fev. 2017. ISSN 2316-753X. Disponível em: <http://revista.unicuritiba.edu.br/index.php/RevJur/article/view/1716/1113 >. Acesso em: 25 abr. 2020. doi:http://dx.doi.org/10.21902/revistajur.2316-753X.v3i44.1716.

FREIRE, N.: Politicas Publicas hacia cambiar el cotidiano de la mujer. Revista Observatório Social, n. 5, 2004.

Fundação Sistema Estadual De Análise De Dados - SEADE. Disponível em: https://www.seade.gov.br/produtos/mulher-trabalho/. Acesso em: 19 jan. 2020.

GUARAGNI, Fabio Andre; DE BARROS, Ellen Galliano; MOSER, Manoela Pereira. Responsabilidade penal da pessoa jurídica por crimes ambientais à luz do modelo construtivista de autorresponsabilidade. Revista Relações Internacionais no Mundo Atual, [S.1.], v. 1, n. 22, p. 16 - 35, jan. 2019. ISSN 2316-2880. Disponível em: <http://revista.unicuritiba.edu.br/index.php/RIMA/article/view/3859/371372194>. Acesso em: 25 abr. 2020. doi:http://dx.doi.org/10.21902/Revrima.v1i25.3859.

HILST, Pedro E. de Lima. Anticorrupção e compliance. Monografia (Bacharelado em Direito) - UFPR, 2013.

HIRATA, H. \& KERGOAT, D. Divisão sexual do trabalho profissional e doméstico: Brasil, França, Japão. In: COSTA, A., SORJ, B., BRUSCHINI, C., HIRATA, H. (Org.). Mercado de trabalho e gênero: comparações internacionais. Rio de Janeiro: Editora FGV, 2008.

HOUAISS, A. (Org.); VILlAR, M. S. (Ed.). Dicionário Houaiss conciso. São Paulo: Moderna, 2011.

HSU, Kerley G. P. Compliance: nova área de atuação para os profissionais do direito. Artigo (Bacharelado em Direito) - UNIT, 2015.

INTERNATIONAL IDEA; INTER-PARLIAMENTARY UNION; STOCKHOLM UNIVERSITY. Atlas of Electoral Gender Quotas. International Institute for Democracy and Electoral Assistance, 2013. Disponível em: http://www.ipu.org/pdf/publications/atlas-en.pdf. Acesso em: 03 jan. 2020.

LESKINEN, M.: Educación una clave hacia la igualdad, Revista Observatório Social, n. 5, 2004.

MACDONALD, Fiona. Knocking Down Walls in Political Science. In: Defense of an Expansionist Feminist Agenda. Canadian Political Science Association Conference, 2016. Disponível em: https://cpsa-acsp.ca/documents/conference/2016/MacDonald.pdf. Acesso em: 12 dez. 2019.

MARTINS, Clitia H. B.; BANDEIRA, Marilene D.; CAPUTO, Paula M.. Condição de vida das mulheres e desigualdades de gênero no Rio Grande do Sul. In: MARTINS, Clitia H. B. (Coord.). Estudos das condições das mulheres e das desigualdades de gênero existentes no Estado do Rio Grande do Sul - Porto Alegre: FEE, 2013. 
MARTINS, Sérgio Pinto. Direito do Trabalho, 24 ed. São Paulo, Atlas, 2008.

MELLO, A. C. R. C. D. As mulheres na Guerra. Revista Pré UNIVESP, n. 61, dez. 2016.

MURARDO, R. M.: La mujer en el tercer milenio: una historia de la mujer a traves de lo tiempo y perspectiva para el futuro, Rio de Janeiro, ed. Rosa de los Tiempos, 1992.

Organização das Nações Unidas (2017). Glossário de termos do Objetivo de Desenvolvimento Sustentável 5: Alcançar a igualdade de gênero e empoderar todas as mulheres e meninas. Disponível em: https://nacoesunidas.org/wpcontent/uploads/2017/06/Glossario-ODS-5.pdf. Acesso em: 20 dez. 2019.

PEREIRA, P. A. P. Discussões conceituais sobre política social como política pública e direito de cidadania. In: BOSCHETTI, I.; BEHRING, E. R.; SANTOS, S. M. M.; MIOTO, R. C. T. (orgs.). Política Social no Capitalismo: tendências contemporâneas. São Paulo: Cortez, 2008.

PROBST, Elisiana Renata. A Evolução da Mulher no Mercado de Trabalho. Disponível em: https://www.rhportal.com.br/artigos-rh/a-evoluo-da-mulher-no-mercado-de-trabalho/. Acesso em: 18 jan. 2020.

RAMOS, G. S. Leitura feminista da história do Brasil. Rev. Estudos Feministas, v.21, n.3, Florianópolis, 2013.

RYNDACK, Jaqueline Maria; GUARANI, Fábio André. Compliance e políticas públicas: caminho preventivo no combate de crimes no âmbito empresarial?. Percurso, [S.1.], v. 3, n. 30, p. 220 - 224, dez. 2019. ISSN 2316-7521. Disponível em: <http://revista.unicuritiba.edu.br/index.php/percurso/article/view/3660/371372035>. Acesso em: 25 abr. 2020.

SANTOS, Juliana A. dos. Desigualdade social e o conceito de gênero. Virtú (UFJF), v. 1, 2006. Disponível em: http://www.ufjf.br/virtu/files/2010/05/artigo-3a7.pdf. Acesso em: 18 jan. 2020.

SEN, Amartya. Desigualdade reexaminada. Rio de Janeiro: Editora Record, 2001.

SOARES, Marcelo Negri; CAMPOS, Marisa Gisela. Compliance na realização da função social da empresa. Percurso, [S.1.], v. 1, n. 28, p. 1 - 21, jun. 2019. ISSN 2316-7521. Disponível

em:

$<$ http://revista.unicuritiba.edu.br/index.php/percurso/article/view/3416/371371846>. Acesso em: 25 abr. 2020.

TOMEI, Manuela. El trabajo de la OIT hacia alcanzar la igualdad de gênero. Revista Observatório Social: São Paulo, n. 5, 2004.

WORLD ECONOMIC FORUM. The Global Gender Gap Report 2018. Disponível em: http://www3.weforum.org/docs/WEF_GGGR_2018.pdf. Acesso em: 20 jan. 2020.

ZILLI, S. M.: Mujer, discriminación y derecho del trabajo, Rev. Observatório Social, n.5, 2004. 